\title{
¿QUÉ SE DICE CUANDO SE DICE FILOSOFÍA LATINOAMERICANA?
}

\author{
José Santos Herceg \\ IDEA / USACH \\ Jose.santos@usach.cl
}

\begin{abstract}
Resumen
El presente texto busca mostrar los diferentes "usos" que se aparejan a la expresión "filosofía latinoamericana". El objetivo de este análisis no es determinar si alguno de ellos es más o menos correcto, si uno es más o menos adecuado, sino simplemente de poner de manifiesto que la expresión "filosofía latinoamericana" tiene distintos usos y que cada uno de ellos remite a diferentes problemas filosóficos.

Palabras clave: filosofía latinoamericana, usos, sujeto filosofante.
\end{abstract}

\section{Abstract}

This paper aim to examine the different uses of the expression "filosofia latinoamericana". The porpousse of the study ist not to determinate if one of these uses ist right or wrong, but just to show that the expression "filosofia latinoamericana" has different uses and that these uses brings us to diferent philosophical problems.

Key words: Latin american philosophy, usages, philosopher.

RT Alejandro Korn escribía a principios del siglo XX respecto de la filosofía en Argentina algo que creo se puede aplicar a muchos de los que comienzan a leer un artículo como este: "Me imagino - decía Korn- la sonrisa del lector (...). ¿Desde cuándo tenemos filosofía argentina? ¿Acaso tenemos filósofos?” (Korn 1993: 29). Reacción irónica que con toda probabilidad será la de una parte importante de los que se topen con este texto. La filosofía latinoamericana, sin embargo, para sorpresa de muchos, constituye desde hace un buen tiempo un tema de investigación y a la fecha tiene a su haber, tanto considerando los textos originales de los filósofos como el metadiscurso o examen crítico de dichos escritos, un enorme caudal de literatura. Utilizando criterios que recuerdan al concepto de "normalidad" de Francisco Romero, podríamos decir que se dictan cursos de filosofía latinoamericana por todo el continente, se han escrito innumerables historias de la filosofía latinoamericana (tanto continentalmente considerada como por países), se realizan congresos y coloquios sobre el tema regularmente y los libros al respecto llenan bibliotecas.

El estudio de la filosofía latinoamericana, es, hoy por hoy, siguiendo con la categorización de Romero, algo muy "habitual” en algunos lugares del continente donde 
dicho trabajo se ha "generalizado": digamos que allí se ha "normalizado" en el sentido de que el dedicarse a ella se ha incorporado como "(...) una actividad ordinaria a la común vida del espíritu” (Romero 1952: 61), se ha ido consolidando hasta pasar a ser “(...) uno de los asuntos habituales del común ejercicio intelectual (...)”(Romero 1952: 54). Es tanto así que la filosofía latinoamericana incluso ha trascendido los límites del continente. En este sentido, a inicio del siglo XXI Pablo Guadarrama hace ver que "(...) los filósofos latinoamericanos han podido insertarse mejor en el nivel de las discusiones filosóficas internacionales” (Guadarrama 2001: 177), que “(...) las ideas filosóficas elaboradas en América Latina han llegado a tener mayor reconocimiento mundial”, que “(...) en Europa y Norteamérica, se ha incrementado el interés por estudiar y valorar el pensamiento filosófico latinoamericano", y que hay un "(...) reconocimiento del grado de madurez alcanzado por la vida filosófica latinoamericana en la actualidad" (178).

Esta instalación y reconocimiento del tema contrasta, sin embargo, con la situación en algunos países de América Latina. Un caso paradigmático es el de Chile. En nuestro país, de hecho, aunque se han publicado algunos libros significativos sobre el tema ${ }^{1}$, se trata de tan pocos que no se puede hablar realmente de una línea editorial instalada, sino más bien de obras que irrumpen esporádicamente. Los cultores de esta temática son un grupo relativamente pequeño de filósofos ${ }^{2}$ y lo limitado de este grupo hace difícil poder hablar de una tradición de desarrollo del tema en nuestro país ${ }^{3}$. Por otro lado, la investigación en el tema prácticamente no ha sido financiada por los fondos

1 Sin la intención de ser exhaustivo, podría mencionarse aquí los siguiente libros: Manfredo Kempf Mercado, Historia de la filosofí latinoamericana, (Zig-Zag, 1958), Carlos Ossandón, Hacia una filosofía latinoamericana (Nuestra América, Santiago de Chile, 1984), Mario Berríos Caro, Identidad-Origen-Modelos: pensamiento latinoamericano (Instituto Profesional de Santiago, 1988), Iván Jaksic, Filosofia e identidad cultural en América Latina (Caracas: Monte Ávila, 1988), Luis Vitale, Pensadores latinoamericanos contemporáneos (Facultad de Filosofía y Humanidades, Universidad de Chile, 2001), Sergio Vuskovich, Filosofía Latinoamericana (Ediciones de la Universidad de Playa Ancha, Valparaíso, 2004), Ricardo Salas A. Ética intercultural (URSH, 2004), la trilogía de Eduardo Devés V, El pensamiento latinoamericano del siglo XX (Biblos-DIBAM, 2003-2004) y recientemente de José Santos Herceg, Conflicto de Representaciones. América Latina como lugar para la filosofía (FCE, México/Chile, 2010).

2 Habría que mencionar aquí a Osvaldo Fernández, Mario Berríos, Carlos Ossandón, William Thayer, Carlos Ruiz, Renato Cristi, Eduardo Devés, Ricardo Salas. Cecilia Sánchez, Javier Pinedo, Patricia Bonzi, Claudio Rivas, Gonzalo Catalán, Marcos García de la Huerta, Jorge Vergara, Sergio Vuscovic e Ivan Jaksic, entre algunos otros.

3 Aunque se podría sostener con Devés y Salas que la posibilidad de una filosofía latinoamericana es uno de los "temas que ha marcado la discusión filosófica los últimos 16 años" en Chile, sin embargo, no se debe olvidar lo que estos mismos autores sostienen un poco antes, es decir, que "los profesores de filosofía se han especializado en estudiar y difundir los temas tradicionales". Son las temáticas de la metafísica, gnoseología, antropología, filosofía del lenguaje, teoría política a la luz de los autores "clásicos" lo que sin duda prima en el trabajo de los chilenos (Devés y Salas, "La filosofía en Chile (1973-1990)", El pensamiento Chileno en el siglo XX, FCE, México, 1999, p. 204). 
abiertos y concursables, en concreto FONDECYT ${ }^{4}$, en su primeros 25 años (1982-1996) patrocinó dos proyectos en el área de la filosofía latinoamericana ${ }^{5}$ y cinco en los que al pensamiento chileno se refiere ${ }^{6}$. Las cátedras en las carreras de filosofía, ya sea a nivel de pregrado (Licenciatura o Pedagogía) ${ }^{7}$ o postgrado ${ }^{8}$, se limitan a ofrecer un curso sobre el tema pero solo en cinco universidades en el contexto de una veintena en las que se enseña filosofía a nivel universitario. Coloquios en los que se aborde la problemática de la filosofía latinoamericana han existido, aunque su número y regularidad hacen imposible hablar en un tema instalado en nuestro país, habría que referirse más bien a una serie de contactos aislados. En contextos como este, la alusión inicial a Korn está justificada. Haciéndome eco de sus palabra diría, por lo tanto, que me imagino la sonrisa del lector ante el título de este artículo. ¿Desde cuándo tenemos pensamiento filosófico en América latina? ¿Acaso tenemos filósofos?

Sin ningún ánimo de ofrecer una respuesta a esta pregunta, ni de entrar en una añeja y ya desperfilada disputa acerca de si existe o no un pensamiento filosófico latinoamericano y menos aún en una suerte de apología de éste, quisiera simplemente

$4 \quad$ Fondo Nacional de Desarrollo de Ciencia y Tecnología. Cf.: www.fondecyt.cl

5 Se trata del proyecto de Joaquín Barceló titulado "Las posibilidades de un pensamiento filosófico hipanoamericano según Ernesto Grassi” (1997) y el de José Santos Herceg, "Filosofía latinoamericana y filosofía africana, diálogo intercultural desde la "falta de respeto" (2008). Hay también algunos otros proyectos que se han financiado cuyas temáticas se relacionan con América latina, entre ellos están: "Visión de la vida y su tarea, que gravitó en el dominio español de América. Hacia una hermenéutica de la relación providencia divina tarea histórica, entre 1942 y el siglo de oro español", de Aníbal Edwards (1991), "La defensa de los indios en el siglo xvi y la idea dieciochesca de "derechos humanos": continuidad vs. descontinuidad. Un espejo de la pasión fundadora de la modernidad y de su relativa ceguera epistemológica”, de Hernán Neira (1995), "La globalización como una filosofía de la historia: bases americanas", de Juan Manuel Fierro y Hernan Neira (2008), y los proyectos "La nacionalidad filosófica", de Marcos García de la Huerta (1990) y "Filosofía y nacionalidad", de Cecilia Sánchez (1995).

$6 \quad$ Se trata de lo siguientes proyectos: Luis Celis, "El pensamiento católico chileno en la primera mitad del siglo xx; hombres e ideas (filosofía, historia, pensamiento social), Dietrich Lorenz, "Agustin Narbarte s.j. (1692-1740) comentador chileno de la metafísica de Aristóteles. 'disputationes in universam aristotelis metaphysicam' iversam aristotelis metaphysicam" (2003), Susana Munich, "Lectura filosófica femenina chilena de María Luisa Bombal" (1990), Javier Pinedo "Historia del pensamiento en Chile 1970-1993", Carlos Ruiz S., "Teorías educacionales y modelos políticos en Chile: 1960-1990”, Cecilia Sánchez, "Recepción de filosofía anglo-francesa en la obra de Ventura Marín" (1992), Mirko Skasica, "Conocimiento y verdad en fray Alonso Briceno" (1991).

7 La excepción la constituyen la Universidad Alberto Hurtado (Filosofía Iberoamericana I y II), la ARCIS, la de La Serena (Filosofía latinoamericana), de Valparaíso (Pensamiento Hispanoamericano) y la Cardenal Silva Enríquez (Cultura y Pensamiento latinoamericano y chileno).

8 Solo el Magíster en Filosofía en la Universidad Alberto Hurtado contempla un curso en su malla sobre Problemas de la Filosofía latinoamericana. 
hacer algunas aclaraciones terminológicas que permitan confeccionar una suerte de mapa o más bien una hoja de ruta. Comenzar por estas aclaraciones adquiere sentido a raíz de un riesgo del que Ernst Tugendhat nos previene expresamente, esto es, que “(...) una palabra se revela como útil para nuestro autoentendimiento, todo el mundo la usa y nadie la explica" (Tugendhat 1996, p. 29). Esta oscuridad parece ser una motivación extra para utilizarla con más frecuencia, pues permite extremar la extensión de su uso $\mathrm{y}$, como dice nuevamente Tugendhat, “(...) se puede tener la pretensión de decir algo aunque no se diga nada, o, peor aún que no decir nada, se puede divagar en la confusión" (Tugendhat 1996, p. 30). De allí que tenga sentido preguntarse por el término "filosofía latinoamericana". Puntualmente, a partir de una inspiración claramente wittgenstaniana, la pregunta será ¿qué se dice cuando se dice "filosofía latinoamericana”?

El término ha rondado por el continente desde que Alberdi lo utilizara por primera vez alrededor de 1842 (Alberdi 1995, pp. 145-151), se ha usado desde entonces y se ha difundido sobre todo en la segunda mitad del siglo pasado. Se habla normalmente de una "filosofía latinoamericana", se ha discutido largamente acerca de su existencia o inexistencia, se ha escrito muchísimas veces su historia y discutido latamente acerca de sus temas principales. El término se utiliza hoy en forma habitual, pero casi nadie lo explica. "Dualidad de saberes", diría Wittgenstein: uno que se tiene y permite hacer uso correcto del término y uno que no se tiene que haría posible explicarlo. De allí que se pueda utilizar correctamente la expresión que corresponde al concepto, pero no se tiene el saber necesario como para aclararle a otro la manera correcta de utilizar dicha expresión. Como el clásico caso del tiempo para San Agustín quien confesaba saber lo que era solo hasta que se lo preguntaban expresamente, momento en que caía en la cuenta que no podía explicarlo (San Agustín 1988, p. 392).

Esto no significa que no existan trabajos tendientes a aclarar el término “filosofía latinoamericana". Al menos cuatro textos pueden mencionarse: uno de Carlos Ossandón, otro de Hugo Biagini, un tercero de Germán Marquínez Argote y, finalmente, uno desaparecido de Jorge Millas. Sin ser fiel a ninguno de ellos en particular, pero utilizándolos como antecedentes o insumos, distinguiré algunos sentidos en que se dice filosofía latinoamericana e intentaré caracterizarlos, poniendo el énfasis en los problemas que les vienen aparejados. La idea es mostrar los diferentes "usos" que se aparejan a la expresión "filosofía latinoamericana", no con el objetivo de determinar si alguno de ellos es más o menos correcto, si uno es más o menos adecuado, sino simplemente con la intención de poner de manifiesto que la expresión "filosofía latinoamericana" tiene diferentes usos, que a ella le corresponden distintos objetos y que cada uno de ellos remite a problemas filosóficamente relevantes.

Comenzaré algo arbitrariamente por el sentido "teleológico" del término "filosofía latinoamericana", como lo llama Biagini, es decir, aquel sentido que "(...) se suscita como un programa de acción, ante una situación considerada deficitaria” (Biagini 1989, p. 15). 
De lo que se trata aquí es de una "filosofía para América Latina". El hito fundacional o inaugural de este uso del término es, sin lugar a dudas, Juan Bautista Alberdi. Él fue quien al utilizar por primera vez la expresión "filosofía americana" en aquel famoso texto titulado "Ideas para un curso de filosofía contemporánea", lo hace, justamente, en este sentido. Alberdi comienza a hablar de repente -sin que medie provocación o exista tradición alguna- de una "filosofía americana", con ello, como el mismo dice, "nacionaliza" la filosofía, le otorga carta de ciudadanía, la enraíza, la especifica, la empadrona, y lo hace en virtud de su "utilidad", del servicio que habría de prestar a América. De allí que para algunos autores la filosofía en América Latina comienza justamente aquí, cuando se toma conciencia de la necesidad de hacer una filosofía "de sí y para sí”. Arturo Andrés Roig señala al respecto que “(...) el comienzo de la filosofía latinoamericana dependería de que se haya constituido una conciencia de sí y para sí, aún cuando muestre grados y momentos diversos. De acuerdo con este punto de vista, la filosofía latinoamericana habría comenzado (...) con los escritos de Juan Bautista Alberdi de los años 1838 y 1840” (Roig 1986, p. 63).

Para Alberdi es necesario estudiar la filosofía europea, pero no se lo debe hacer de cualquier manera, sino que "(...) a fin de que este estudio, por lo común tan estéril, nos traiga alguna ventaja positiva, vamos a estudiar, como hemos dicho, no la filosofía en sí, sino la filosofía aplicada a los objetos de un interés más inmediato para nosotros" (Alberdi 1995, p. 148). La filosofía política se vuelve así la de nuestra política, del mismo modo como la de la religión se transforma en filosofía de nuestra religión. De acuerdo con esta tesis, la filosofía europea se "aplica" en América por los americanos, por eso es que Alberdi puede decir que "(...) la América practica lo que piensa Europa”. Aquí se encuentra el germen de la conocida tesis de la "instrumentalización". Como dicen tanto Cecilia Sánchez como Leopoldo Zea, la idea es que se "toma prestado"(Cf.: Sánchez 1992, p. 40 y Zea 1989, p. 32) de la filosofía europea el indispensable arsenal para filosofar. Es evidente, sin embargo, que cualquier tipo de préstamo es intencionado, obedece a una finalidad que remite a una necesidad correlativa. En virtud de las necesidades concretas, de los problemas puntuales se elige, se requiere y se importa. No cualquier doctrina llega a América, sino aquellas que están de acuerdo con los intereses de los americanos. Del caudal acumulado durante la historia de la filosofía se eligen aquellas herramientas teóricas que mejor sirven para enfrentar los problemas que se tenga. El filósofo latinoamericano echa mano, toma en préstamo, se apropia de determinados conceptos, categorías, argumentos, para "aplicarlos" en la solución de aquellos asuntos que le interesa resolver. La filosofía europea se constituye así en una herramienta en manos americanas 9 . Sus conceptos son, en términos de Jorge Millas, los “(...) útiles instrumentos de trabajo, como si dijéramos herramientas de precisión” (Millas 1969,

9 “(...) quienes sienten el llamado del pensamiento reflexivo en Hispanoamérica no pueden dispensarse de adquirir las técnicas desarrolladas por la filosofía en su larga historia, ni pueden dejar de lado todos aquellos conceptos capaces de servir como soporte de una teoría rigurosa. (...) Pero todo el tiempo han de tener conciencia de su carácter provisional e instrumental y no tomarlos como modelos y contenidos que hay que imitar y repetir 
p. 115). Lo que haría el filósofo latinoamericano es, en palabras de Cecilia Sánchez, simplemente "(...) valerse de la filosofía europea" para su propio interés. La historia de la filosofía adquiere de este modo un "valor de uso" (Sánchez 1992, p. 30).

"No hay, pues, filosofía universal", sentencia Alberdi, pues ella emana y "ha emanado de las necesidades más imperiosas de cada período y de cada país" (Alberdi 1995, p. 148). De allí el surgimiento de una filosofía americana, una que se haga cargo de las "necesidades sociales de nuestros países". Ellas son las que otorgan la nacionalidad a la filosofía: “(...) la filosofía se localiza por el carácter instantáneo y local de los problemas que importan especialmente a una nación” (Alberdi 1995, p. 150). Alberdi llega incluso a hacer una enumeración taxativa de los objetos de estudios prioritarios para una filosofía americana. Se pregunta, ¿cuáles son los problemas que América está llamada a establecer y resolver en estos momentos? Y responde, “(...) los de la libertad, de los derechos y goces sociales de que el hombre puede disfrutar en el más alto grado en el orden social y político; los de la organización pública más adecuada a las exigencias de la naturaleza perfectible del hombre, en el suelo americano" (Alberdi 1995, p. 149).

El sentido teleológico de la filosofía latinoamericana, en tanto que filosofía "para" América Latina, experimenta así una suerte de desplazamiento o más bien una complementación. Si ella surge del diagnóstico de un problema, de una situación deficitaria y se plantea como un camino de solución, entonces el sentido teleológico de la expresión "filosofía latinoamericana" está imbricado con uno de carácter "temático". La filosofía latinoamericana, en tanto que se la comprenda como una reflexión "para" América, supone que los temas que producen molestia e incomodidad en el continente son lo que dan lugar a una reflexión que busca salidas, soluciones. Nos desplazamos así a un segundo modo en que se dice "filosofía latinoamericana": filosofía "acerca de lo" latinoamericano.

De acuerdo con Ossandón, por filosofía acerca o sobre América Latina se entiende aquel pensar que se realiza en o fuera del continente, “(...) cuyo objeto o problema filosófico es desentrañar nuestra realidad" (Ossandón 1984, p. 13), se trata de aquella reflexión que tiene como eje central nuestro mundo americano. Aquí es donde se podrían situar, por ejemplo, las reflexiones acerca de la identidad latinoamericana, sobre la modernidad en América Latina, las dilucidaciones en torno a problemas como el del mestizaje, la integración, el caudillismo, el sincretismo religioso, entre muchos otros. Aquí habría que situar, también, la conocida disputa acerca de la filosofía latinoamericana misma, su originalidad, su autenticidad. América Latina será el tema,

como absolutos, sino como herramientas que hay que utilizar en tanto no hayan otras más eficaces y más adecuadas (...)”(Salazar Bondy 1995, pp. 213-14). 
el problema filosófico relevante para los pensadores. Estos se vuelven hacia la realidad americana, aquella en la que se encuentran inmiscuidos, para descubrir allí los asuntos que se les aparecen como filosóficamente relevantes. Desde aquí es posible comenzar a comprender la tesis de A. A. Roig respecto de que la filosofía en el continente habría tenido múltiples "recomienzos": ella habría surgido cada vez que un sujeto se ha puesto a sí mismo como valioso (a priori antropológico lo llama el mendocino) y ha considerado que tiene valor el pensar sobre sí mismo y su mundo.

Esta perspectiva temática para entender el pensamiento filosófico en América Latina puede rastrearse a lo largo de una nutrida tradición que va desde aquello que Silvio Zabala gustaba en llamar "filosofía de la conquista", pasando por el pensamiento filosófico de la emancipación (tanto política como mental), atravesando todo el siglo XIX y XX. José Martí escribía al respecto que “(...) cuando aparece en Cojímar un problema, no se va a buscar la solución a Danzing. Las Levitas son todavía de Francia, pero el pensamiento comienza a ser de América. Los jóvenes de América se ponen la camisa al codo, hunden las manos en la masa y la levantan con la levadura de su sudor. Entienden que se imita demasiado, y que la salvación está en crear. Crear es la palabra de pase de esta generación. El vino, de plátano; y si sale agrio, ¡Es nuestro vino!” (Martí 1995, p. 125). También en el ámbito filosófico la búsqueda de soluciones creativas, nuevas, sería el único camino viable para resolver los problemas latinoamericanos, dando con ello origen a una reflexión propia, nueva, original.

Un momento históricamente señalado en el sentido de la instalación de una filosofía acerca de lo latinoamericano -tal vez se pueda hablar de un re-comienzo en el sentido de Roig- se encuentra en aquel grupo de filósofos mexicanos que Francisco Miró Quezada llamó “afirmativos”. Ellos, dice el peruano, “(...) proclaman que solo la meditación sobre nuestra propia realidad puede producir la auténtica filosofía”" (Miró Quesada 1974, p. 87). José Gaos - quien tuviera una influencia indesmentible sobre este grupo-sostenía que lo original de la filosofía latinoamericana será la preocupación por lo propio: "Americana será la filosofía que americanos, es decir, hombres en medio de la circunstancia americana, arraigados en ella, hagan sobre su circunstancia, hagan sobre América" (Gaos 1945, p. 368). De allí que para los "afirmativos" hacer una filosofía propia será atender a sus circunstancias, en este caso, la circunstancia es México, en particular, y de América Latina, en general. Comienzan, entonces, por el análisis de la realidad mexicana, para luego abordar el de la historia de las ideas filosófica en México y finalmente ampliarse al continente. La consecuencia inmediata de esta preocupación por "lo propio" es la vinculación, el arraigo: “(...) si la autenticidad -comenta Miró Quesada- consiste precisamente en interpretar esta misma realidad, la filosofía latinoamericana debe desentrañar el sentido de lo que significa ser latinoamericano, entonces nuestro filosofar queda enclavado en el corazón mismo de la realidad" (Miró Quesada 1974, p. 104). 
Esta idea tiene una reorientación hacia finales de los años 60 y principios de los 70 , giro que queda sancionado en la Declaración de Morelia ${ }^{10}$. "A una filosofía que hace suponer el destino manifiesto de un conjunto de pueblos para imponer su dominación al resto del mundo, deberá ofrecerse una filosofía que niegue tal destino y haga, por el contrario, expreso el derecho de todo pueblo a la libertad como autodeterminación. A una filosofía que justifique, como lo ha venido haciendo, la dependencia de unos pueblos en exclusivo beneficio de otros, deberá oponerse una filosofía que rechazando la relación vertical de dependencia haga expresa una relación horizontal de solidaridad" (Roig 1981b, p. 95). La filosofía latinoamericana, en tanto que se hace cargo del problema de la dominación colonial de la que ha sido objeto el continente, se vuelve, entonces, "filosofía de la liberación", haciendo de ella su objeto de trabajo, su problema central por ineludible. La realidad de la dependencia, se señala en la Declaración, ha sido asumida en el continente latinoamericano por un vasto grupo de intelectuales que han intentado o intentan dar una respuesta filosófica, precisamente, como "filosofía de la liberación".

La reflexión "acerca de" lo latinoamericano supera con la filosofía de la liberación una simple vinculación temática al modo de un objeto de estudio que pueda o no tomarse, y se vuelve una exigencia que surge de la constatación de los rasgos dolorosos de su realidad, de la situación de colonización y dependencia en la que se encuentra América Latina. Con ello se opera un nuevo desplazamiento. Si la filosofía "sobre" América Latina implica una preocupación filosófica por lo propio, por el lugar en el que se está y nos es propio -tanto para conocerlo como para cambiarlo-, el sentido temático transita hacia un nuevo modo de decir filosofía latinoamericana, en tanto que filosofía “en” América Latina.

Al hablar del sentido geográfico, a lo que se refiere Biagini es a la filosofía "hecha en América Latina", aquella que se ha dado en nuestro continente. La nacionalidad proviene, esta vez, de la tierra, de la madre tierra. Ius solis, como se le denomina en jerga legal. Quienquiera que venga al mundo adquiere la nacionalidad del terruño en el que cayó, en el que vio la luz por primera vez. Es latinoamericana la filosofía que surge en los territorios que son parte de lo que se ha llamado América Latina. Del mismo modo como es inglesa la que nace en Inglaterra, griega o alemana la que ve la luz en los respectivos terruños, es latinoamericana la filosofía que brota en tierras de América Latina. Esta manera de decir filosofía latinoamericana, como filosofía "en" América Latina, aparece espontáneamente y tiene un carácter aparentemente nítido,

10 Esta declaración fue firmada por Enrique D. Dussel, Francisco Miró Quesada, Arturo Andrés Roig, Abelardo Villegas, Leopoldo Zea, con motivo del Primer Coloquio Nacional de Filosofía, celebrado en la ciudad de Morelia, Michoacán (México), del 4 al 9 de agosto de 1975. 
libre de problemas teóricos, sin compromisos y basada solo en un criterio geográfico. Con ello se pretende aludir solo a un asunto cartográfico: una filosofía que nace dentro de los límites de la América Latina, es decir, al sur del río Grande.

Algunos autores han sostenido con razón, sin embargo, que no es casual ni anecdótico que una filosofía tenga como su lugar de enunciación a América Latina; con ello se está diciendo algo de ella, se la está especificando más allá de una simple marca geográfica. En este sentido se podría entender que Raúl Fornet Betancourt asegure que el tiempo y espacio donde se da la reflexión "(...) no son ingredientes que se puedan añadir o no, según gusto, al quehacer filosófico", pues ellos determinan, especifican su "gusto", su "sabor": contornean su "rostro" (Fornet Betancourt 2001, p. 13). No es indiferente que la reflexión emane en determinado lugar del globo. Enrique Dussel escribía que “(...) se trata de tomar en serio al espacio, al espacio geopolítico. No es lo mismo nacer en el Polo Norte o en Chiapas que en New York" (Dussel 1977, p. 12) y, retomando expresamente esta tesis, Walter Mignolo hace ver que “(...) hacer filosofía en América Latina o en África (y también en Estados Unidos) no es lo mismo que hacer filosofía en Alemania, Francia o Inglaterra" (Mignolo 2001, p. 13). El lugar de la enunciación no es secundario: no habría un lugar abstracto, en el sentido de neutro. El espacio y el tiempo, el contexto desde el cual se emite un discurso filosófico es su lugar y en tanto que tal, es central para efecto de su constitución como discurso. América Latina es el lugar en el cual surge la filosofía latinoamericana, con eso le da su nacionalidad, su nombre, pero también le otorgaría su figura y fisonomía, su especificidad.

En este sentido se puede comprender el famoso diagnóstico de Augusto Salazar Bondy. El pensamiento latinoamericano es -sentencia el peruano- "defectivo e inauténtico" y la causa está en "nuestra sociedad y nuestra cultura" (Salazar Bondy 1988, p. 88). Son tres elementos los que a su juicio caracterizan a América Latina: subdesarrollo, dependencia y dominación. "Dependientes de España, Inglaterra o Estados Unidos hemos sido y somos subdesarrollados de estas potencias y, consecuentemente, países con una cultura de dominación" (Salazar Bondy 1988, p. 86). A partir de este lugar - cultura defectiva- no podía más que darse una sociedad "mal formada" que, como dice el peruano, "la filosofía expresa y a la vez sufre" (Salazar Bondy 1988, p. 87). También la tesis de aquellos filósofos como Pedro Trigo, que sostienen la necesidad de un "pensamiento re-ligado" (Trigo 1993, p. 111) solo se comprende sosteniendo el vínculo con el lugar de enunciación. Filosofía re-ligada con el mundo, con la realidad, que para estos autores es una realidad violentada por el llanto de los que no tienen que comer, por la vulnerabilidad de los que no tienen casa, por la falta de perspectiva de los que carecen de educación, etc. La religación de la filosofía es una reacción ante o más bien una re-conexión con el mundo de los menesterosos, los desposeídos, los marginales, que es América Latina. 
La idea de filosofía latinoamericana en tanto que intercultural en el sentido en que ha sido planteada por autores como Raúl Fornet-Betancourt, Dina Picotti, Ricardo Salas, Fidel Tubito entre otros, tiene como fundamento el vínculo -arraigo- del pensamiento con una América Latina que es plural culturalmente hablando. Esta diversidad se expresa necesariamente en un pensamiento filosófico múltiple. En este punto se pone de manifiesto que lo geográfico lleva a un nuevo desplazamiento en el sentido del término "filosofía latinoamericana". Un nuevo modo de decir filosofía latinoamericana está allí implícito, pues el lugar, el contexto es relevante solo en tanto que se trata del lugar de un "alguien" que filosofa. No hay lugar sin sujeto, o dicho de otro modo, el lugar solo puede serlo para uno o más sujetos, luego -por evidente que parezca- no hay filosofía sin filósofos. El sentido geográfico lleva implícito entonces un sentido "personificador", como ha sido llamado por Hugo Biagini.

A lo que apunta este nuevo sentido de la expresión "filosofía latinoamericana" es al sujeto mismo y denota una "filosofía hecha por latinoamericanos". En este sentido es que se ha hablado de una herencia paterna, un ius sanguinis, donde el pensamiento adquiere su apellido por parte del padre, esto es, de su autor. Si el filósofo es latinoamericano, por añadidura y automáticamente su pensamiento también lo será. En este mismo sentido es que se habla en el contexto mundial, por ejemplo, de una filosofía alemana, inglesa, francesa o china. Los alemanes hacen la filosofía alemana y un Hegel, un Heidegger, un Kant o un Nietzsche hacen filosofía alemana en tanto que ellos son alemanes. De acuerdo con esta denominación no importaría en realidad cuáles sean los problemas de los que se trate, ni la época en que se escriba y menos aún el método de análisis. Sería tan inglesa la filosofía de Hume, como la de Searl, y tan francesa la de Rouseau como la de Derrida. Desde esta perspectiva, los latinoamericanos no pueden más que hacer "filosofía latinoamericana": es imposible dejar de hacerlo aunque se lo desee, aunque uno se encuentre al otro lado del mundo, aunque lo hagamos en un idioma que no sea el español, aunque no sea de muy buena calidad y su profundidad no sea la deseable. Un filósofo latinoamericano haría, por lo tanto, siempre "filosofía latinoamericana".

Queda a la vista el problema del sujeto, en particular, del sujeto filosofante. Desde una cierta tradición academicista del filosofar, la primera persona del singular se oculta y debe ser ignorada, tiende a esconderse para no ser vista, sino solo oída, aunque solo como una voz neutra o más bien neutralizada por un inpersonal. En este sentido, para un filósofo que se hace cargo, por ejemplo, de los problemas de la moral, el que sea alemán, chino, australiano o venezolano es del todo irrelevante. El sujeto filosofante, su origen, no tiene importancia alguna para una reflexión que se presenta como autónoma, a-pátrida y huérfana. Un pensamiento que se integra a la arcas de conocimiento universal. En este caso, el filósofo no tiene incidencia alguna sobre la reflexión misma y solo tendrá alguna repercusión en tanto que le hereda -pero solo de una manera algo anecdótica- su nacionalidad. Desde esta perspectiva, el pensamiento de un filósofo latinoamericano no podrá nunca renegar del origen de su progenitor, pero su lugar será el de la filosofía universal. 
Para Humberto Giannini, por el contrario, la filosofía “(...) no debe desterrar completamente de sus consideraciones el modo en que el filósofo viene a encontrarse implicado y complicado en aquello que ex-plica" (Giannini 1999, p. 11), pues solo así conserva su profundidad y seriedad. La filosofía sería, según este autor, "diarística". En un sentido análogo, Arturo Andrés Roig, en sintonía con la tesis de Hegel, sostiene que para que haya filosofía es indispensable un "sujeto". Con ello, Roig está aludiendo al sujeto empírico, es decir, histórico (lo que lo distancia de Hegel). Se trata del sujeto que "se pone a sí mismo como valioso" y "considera como valioso el pensar sobre sí mismo". El "acto valorativo originario" -nuevamente el "a priori antropológico"-, sería el antecedente necesario e indispensable para la existencia de la filosofía. Punto de partida y punto de llegada del filosofar según Roig: topía y utopía del pensar filosófico de acuerdo con la lectura de Pérez Zavala. La filosofía latinoamericana en tanto que "hecha por" latinoamericanos, por lo tanto, no solo la cualifica como latinoamericana, sino que, en tanto que lo hace, la cualifica como filosofía: sin un sujeto filosofante no habría filosofía. En este sentido es que debe entenderse la tesis de los "re-comienzos" de la filosofía latinoamericana sustentada por A. A. Roig: ella ha surgido cada vez que un sujeto se ha puesto a sí mismo como valioso y ha considerado que tiene valor en pensar sobre sí mismo. Es así como se podría hablar de un comienzo con las ideas independentistas, de otros durante la etapa de la organización nacional, de un tercero durante la independencia tardía de Cuba y Puerto Rico, etc. (Cf. Roig 1981a).

Se podrían, sin duda alguna, seguir describiendo usos de la expresión "filosofía latinoamericana", algunos de ellos presentes en los textos de los autores antes referidos. El recorrido aquí presentado no pretende, sin embargo, ser exhaustivo, sino ejemplar. Los diferentes usos, como se ha podido ver, se implican unos a otros e incluso es posible desprender de ellos otros que no han quedado especificados. Para terminar, sin embargo, sería interesante recuperar un último uso ya mencionado de una u otra forma, pero que tiene la virtud de englobar todas las discusiones antes aludidas. El sentido "conceptual", como lo llama Biagini, es el que se relaciona con una "filosofía (propia) de Latinoamérica" y "(...) se refiere a rasgos e inquietudes preponderantes que en relación con otras expresiones nacionales, distinguen nuestro filosofar" (Biagini 1989, p. 16). No se trata específicamente del problema de la "originalidad" del pensamiento latinoamericano como fuera planteado ya desde los años 50 del siglo pasado. A lo que se apunta aquí es a todo aquello que ya se ha dicho: los rasgos que caracterizan la filosofía latinoamericana especificándola dicen relación son sus temas, sus objetivos, con su sujeto, con su lugar de enunciación. Características que permiten ir saliendo del "acorralamiento" del que hablaba Robert Bernasconi al referirse a la situación del pensamiento africano Como dice este autor, el pensamiento periférico se encuentra ante una disyuntiva aporética: o bien se hace filosofía tal como la hacen los europeos y ya no es más que una copia, una imitación, un vil plagio, o se la hace de un modo alternativo, diferente, particular, propio, y entonces se pone en cuestión su carácter de verdadera filosofía (Cf. Bernasconi 1997, pp. 183-196). 
Referencias bibliográficas

Alberdi, Juan Bautista (1995), "Ideas para un curso de filosofía contemporánea", Fuentes de la Cultura Latinoamericana I. Zea, edit., México: FCE; pp. 145151.

Bernasconi, Robert (1997), "African Philosphy's Challenge to Continental Philosphy", Postcolonial African Philosphy. Emmanuel Chukwudi Eze, New York: Routledge; pp. 183-196.

Berríos Caro, Mario (1988), Identidad-Origen-Modelos: pensamiento latinoamericano. Chile: Instituto Profesional de Santiago.

Biagini, Hugo (1989), "La expresión "Filosofía latinoamericana", Filosofía Americana e Identidad. Argentina: EUDEBA; pp. 15-18.

Devés, Eduardo y Salas, Ricardo (1999), "El pensamiento en Chile (1973-1990)”, El pensamiento Chilenos en el siglo XX. México: FCE; pp. 213-252.

Devés V., Eduardo (2003-2004), El pensamiento latinoamericano del siglo XX. Argentina/Chile: Biblos-DIBAM.

Dussel, Enrique (1977), Filosofía de la Liberación. México: Editorial Edicol.

Dussel, Miró Quesada, Roig, Villegas y Zea (1981), “Declaración de Morelia”, (1981), México, de agosto de 1975. Publicada en Arturo Roig, Filosofía, Universidad y Filósofos en América Latina. México: UNAM; pp. 95-101.

Fornet Betancourt, Raúl (2001), Transformación intercultural de la filosofía. España: Desclée.

Gaos, José (1945), Pensamiento en lengua española. México: Stylo.

Giannini, Humberto (1999), La Reflexión cotidiana. Hacia una arqueología de la experiencia. Santiago: Editorial Universitaria, (5 a edición).

Guadarrama, Pablo (2001), "Balance y perspectiva de la filosofía latinoamericana al final del milenio"; Cuadernos Americanos N 85; pp. 165-183.

Jaksic, Iván (1988), Filosofía e identidad cultural en América Latina. Caracas: Monte Ávila.

Kempf Mercado, Manfredo (1958), Historia de la filosofía latinoamericana. Santiago de Chile: Zig-Zag.

Korn, Alejandro (1993), "Filosofía Argentina”, Qué es eso de... Filosofía Latinoamericana. Colombia: El Búho (1981).

Marquínez Argote, Germán (1981), "Presentación”, ¿Qué es eso de... Filosofía latinoamericana? Bogotá: El Búho; pp. 6-7.

Martí, José (1995), "Nuestra América", Fuentes de la cultura latinoamericana I. Zea (comp.), México: FCE; pp. 119-128.

Mignolo, Walter (2001), "Introducción”, Capitalismo y geopolitica del conocimiento. El Eurocentrismo y la filosofía de la liberación en el debate intelectual contemporáneo. Argentina: Duke University, Ediciones del signo; pp. 9-54. 
Millas, Jorge (1969), Idea de la filosofía. El conocimiento. Santiago de Chile: Editorial Universitaria.

Miró Quesada, Francisco (1974), Despertar y proyecto del filosofar latinoamericano. México: FCE.

Ossandón, Carlos (1984), Hacia una filosofia latinoamericana. Santiago de Chile: Nuestra América.

Roig, Arturo Andrés (1981a), Teoría y Crítica del pensamiento latinoamericano. México: FCE,.

(1981b), Filosofía, Universidad y filósofos en América Latina. México: Nuestra América.

(1986), "Interrogantes sobre el pensamiento filosófico", América Latina en sus ideas. Zea (Comp.) México: Siglo XXI; pp. 47-71.

(1994), El pensamiento latinoamericano y su aventura I y II. Centro editor de América Latina, BBAA.

(2001), Caminos de la Filosofía Latinoamericana. Venezuela: Universidad de Zulia.

Romero, Francisco (1952), Sobre la Filosofía Americana. Buenos Aires: Editorial Raigal (Escrito en 1942).

San Agustín (1988), Confesiones. Madrid: BAC.

Sánchez, Cecilia (1992), Una disciplina de la distancia. Institucionalización universitaria de los estudios filosóficos en Chile. Santiago de Chile: CERC-CESOG.

Salazar Bondy, Augusto (1995), "Sentido y Problema del pensamiento filosófico hispanoamericano", Fuentes de la cultura latinoamericana I. Zea (comp.), México: FCE; pp. 213-14.

(1988), ¿Existe un filosofía en nuestra América? Argentina: Siglo XXI (1968).

Salas A., Ricardo (2004), Ética intercultural. Santiago de Chile: Editorial de la Universidad Raúl Silva Henríquez.

Santos-Herceg, José (2010), Conflicto de representaciones. América Latina como lugar para la filosofía. México/Chile: FCE.

Trigo Pedro (1993), "Filosofía Latinoamericana. Coordenadas", Para una filosofía desde América Latina. Ellacuría y Scannone (comp.), Colombia: Pontificia Universidad Javeriana, 1992. También en Irrupción del pobre y el quehacer filosófico. Hacia una nueva racionalidad, Scannone y Perine, ed., Argentina: Editorial Bonum; pp. 45-70.

Tugendhat, Ernesto (1996), "Identidad: personal, nacional y universal" Persona y Sociedad, Vol X, N 1; pp. 29-42.

Vitale, Luis (2001), Pensadores latinoamericanos contemporáneos. Santiago: Facultad de Filosofía y Humanidades, Universidad de Chile.

Vuskovich, Sergio (2004), Filosofía Latinoamericana. Valparaíso, Chile: Ediciones de la Universidad de Playa Ancha. 
Zavala, Silvio (1994), Filosofia de la conquista. México: FCE (1947).

Zea, Leopoldo (1989), La filosofía latinoamericana como filosofía sin más. México: Siglo XXI (1969). 